\title{
ELECTROCHEMICAL DECONTAMINATION OF WATERS BY ADVANCED OXIDATION PROCESSES (AOPS): CASE OF THE MINERALIZATION OF 2,4,5-T ON BDD ELECTRODE
}

\author{
Birame Boye $^{1^{*}}$, Enric Brillas ${ }^{1 *}$, Beatrice Marselli ${ }^{2}$, Pierre-Alain Michaud ${ }^{2}$, Christos \\ Comninellis $^{2^{*}}$ and Mor Marième Dieng ${ }^{3}$ \\ ${ }^{1}$ University of Barcelona, Department of Physical Chemistry, LCTEM, \\ c. Marti i Franques, 1-11, 08028, Barcelona, Spain \\ ${ }^{2}$ Swiss Federal Institute of Technology, School of Basic Sciences, \\ Section of Chemistry and Chemical Engineering, ISP-CO, CH-1015 Lausanne, Switzerland \\ ${ }^{3}$ University C.A. DIOP of Dakar (UCAD), School of Sciences and Techniques, \\ Department of Chemistry, LCPOAI, BP 5055, Dakar - Fann, Senegal
}

(Received December 10, 2003; revised March 4, 2004)

\begin{abstract}
In the present work, herbicide 2,4,5-trichlorophenoxyacetic acid, more commonly known as 2,4,5-T herbicide, has been completely mineralized (i.e. transformed into $\mathrm{CO}_{2}$ and $\mathrm{H}_{2} \mathrm{O}$ ) in saturated aqueous solutions using a semi-industrial electrochemical cell that contains a boron doped diamond anode and a zirconium cathode. We have performed cyclic voltammetry, chronoamperometry and bulk electrolysis to give the optimization characteristics of the degradation of such a compound and its by-products. Bulk electrolysis in the potential region of electrolyte decomposition leads to the complete destruction of 2,4,5-T and its degradation intermediates by means of the electrogeneration of the highly reactive hydroxyl radicals. The evolution of the chemical oxygen demand (COD) and the instant current efficiency (ICE) during the degradation process is perfectly predicted by a theoretical mathematical model. HPLC and GC-MS have also been performed to highlight the evolution of the mother product and its degradation intermediates. Kinetic analysis of the obtained results has shown a fast destruction of the mother herbicide asserting a diffusion-controlled process. 2,4,5-trichlorophenol and quinonebased organic compounds have been depicted as aromatic intermediates, all of them transformed into short chains carboxylic acids before complete mineralization happens.
\end{abstract}

KEY WORDS: Electrochemical decontamination, Cyclic voltammetry, 2,4,5-T herbicide, Mineralization, BDD electrodes

\section{INTRODUCTION}

Chlorine derivative and/or reminiscent organic compounds are known as cancer suspect agents and are difficult to remove by classical and biological methods of wastewater and industrial effluents treatment. This is beginning to constitute an acute ecological and environmental problem. Great efforts are performed to seek alternative and energetically beneficial ways to resolve such problems that derive from the use of insecticides outdoors and indoors, herbicides and generally pesticides in whole human activities. Chemical and physical methods of wastewater treatment are being progressively replaced by the so-called advanced oxidation processes (AOPs) and advanced electrochemical oxidation processes (AEOPs). Progress in the field of electrochemistry has given high over-voltage electrode materials such as $\mathrm{PbO}_{2}$ [1-3], doped $\mathrm{PbO}_{2}$ [2], doped $\mathrm{SnO}_{2}$ [4-7] and $\mathrm{IrO}_{2}$ [8-9], that permit the quick removal of pollutant from aqueous solutions. However, their major inconvenient consists in the fact that the

*Corresponding authors. ${ }^{1}$ Tel.: +39-049-8275117, fax: +39-049-8275135, e-mail: b.boye@qf.ub.es ${ }^{2}$ Tel.: +34-93-4021223; fax: +34-93-4021231, e-mail: brillas@ub.edu 
pollutants are slowly transformed into hardly degradable carboxylic compounds that remain in the treated solutions for many time. Recent techniques on carbon-based materials [10-13] have given high-performances electrodes that permit to eliminate contaminants from aqueous solutions even at trace concentrations. In the ultimate times, the use of boron-doped thin-film layer diamond, which is characterized by extreme stability and mechanical resistance, is largely related as anode in the field of water treatment. Its stability is higher than platinum over-voltage oxidative potential which makes it reliable and of great future in the field of electrochemical decontamination. Boron doped diamond (BDD) electrodes have been related as very powerful to completely achieve the destruction of hardly degradable carboxylic compounds such as formic and oxalic [14] acids based on the oxidation power of the electrogenerated hydroxyls radicals at the diamond surface [15]. Surfactants have also been satisfactorily degraded on BDD anodes in aqueous solutions by batch electrolysis in the potential region of water decomposition ( $2.3 \mathrm{~V} v s$. SHE) in comparison with graphite and other carbon-felt electrodes that suffered abrasion during the electrochemical process [16].

Herbicide 2,4,5-trichlorophenoxyacetic acid, more commonly known as 2,4,5-T or Silvex, is often widely-used as a weed killer for home lawns. It is considered to be less readily biodegradable than the analogous phenoxyacetic acid herbicides. Its high resistance to microbial metabolism likely stems from the additional chlorine on the aromatic ring makes it even more difficult to treat in biological basins. In the present paper, we report the complete mineralization of the herbicide 2,4,5-T in acid aqueous solutions on BDD anodes. The complete degradation of saturated synthetic solutions of 2,4,5-trichlorophenoxyacetic acid herbicide in aqueous medium with perchloric acid as electrolyte support is related. Cyclic voltammetry, bulk electrolysis, and chromatography (HPLC and GC-MS) have been performed to give the behavior of 2,4,5-T on BDD anode. COD and ICE evolution is perfectly reproducible with a mathematical method developed by Comninellis et al. [17].

\section{THEORETICAL}

Experimental parameters such as the chemical oxygen demand (COD) and the instant current efficiency (ICE) are also given theoretically by a mathematical model for the degradation of organic pollutants in the used batch recirculation electrochemical system functioning under galvanostatic conditions as represented in Table 1.

Table 1. Equations [17] related to the COD-time and ICE-time $(t)$ evolution during organic compounds oxidation at the BDD electrode. $V_{\mathrm{R}}$ is the reservoir volume (in $\left.\mathrm{m}^{3}\right), A$ is the electrode area $\left(\mathrm{m}^{2}\right)$, $\mathrm{COD}^{0}$ is the initial chemical oxygen demand (in mole $\mathrm{O}_{2} \mathrm{~m}^{-3}$ ) and $\alpha=i / i^{0}$ lim, where $i^{0}$ lim is the limiting current density (in $\mathrm{A} \mathrm{m}^{-2}$ ).

\begin{tabular}{|l|c|c|}
\hline & Instantaneous current efficiency (ICE) & $\begin{array}{c}\text { Chemical oxygen demand } \\
\operatorname{COD}\left(\mathrm{mol} \mathrm{O}_{2} \mathrm{~m}^{-3}\right)\end{array}$ \\
\hline $\begin{array}{l}i_{\text {appl }}<i_{\text {lim }} \text { under } \\
\text { current control }\end{array}$ & $I C E=1$ & $C O D(t)=C^{0} D^{0}\left(1-\frac{\alpha A k_{m}}{V_{R}} t\right)$ \\
\hline $\begin{array}{l}i_{\text {appl }}>i_{\text {lim }} \text { under } \\
\text { mass-transport } \\
\text { control }\end{array}$ & $I C E=\exp \left(-\frac{A k_{m}}{V_{R}} t+\frac{1-\alpha}{\alpha}\right)$ & $C O D(t)=\alpha C O D^{0} \exp \left(-\frac{A k_{m}}{V_{R}} t+\frac{1-\alpha}{\alpha}\right)$ \\
\hline
\end{tabular}


The limiting current density for the complete electrochemical oxidation of 2,4,5-T on the BDD anode surface can be associated with the COD of the electrolyzed solution [17]:

$$
i_{\lim }(t)=4 F k_{m} \operatorname{COD}_{(\mathrm{t})}
$$

Two different cases can be considered during the process: (i) when $i_{\text {appl }}<i_{\text {lim }}$ : the electrolysis is under limiting current control, the ICE is $100 \%$ and the COD decreases linearly; and (ii) when $i_{\text {appl }}>i_{\text {lim }}$ : the process is controlled by mass-transport and the COD removal follows a exponential decay.

Complete mineralization of $2,4,5-\mathrm{T}$ is ensured by the electrochemical generation of oxidative hydroxyl radicals and other active intermediates from the water discharge at the diamond anode :

$$
\mathrm{H}_{2} \mathrm{O} \rightarrow \mathrm{OH}^{\bullet}+\mathrm{H}^{+}+\mathrm{e}^{-}
$$

The whole oxidation process can be then represented as follows :

$$
\mathrm{C}_{8} \mathrm{H}_{5} \mathrm{Cl}_{3} \mathrm{O}_{3}+13 \mathrm{H}_{2} \mathrm{O} \rightarrow 8 \mathrm{CO}_{2}+31 \mathrm{H}^{+}+3 \mathrm{Cl}^{-}+28 \mathrm{e}^{-}
$$

This process is characterized by a fast reaction which is controlled by the mass transport of the pollutant on the anode surface. The limiting current density $\left(i_{\mathrm{lim}}, \mathrm{A} \mathrm{m}^{-2}\right)$ for the electrochemical mineralization of 2,4,5-T is given by :

$$
i_{\lim }(t)=28 F k_{m}\left[\mathrm{C}_{8} \mathrm{H}_{5} \mathrm{Cl}_{3} \mathrm{O}_{3}\right]_{(\mathrm{t})}
$$

where $t$ is the current electrolysis time, 28 is the number of exchanged electrons, $F$ is the faraday constant $\left(96,487 \mathrm{C} \mathrm{mol}^{-1}\right), k_{m}$ is the average mass-transport coefficient in the electrochemical reactor $\left(\mathrm{m} \mathrm{s}^{-1}\right)$ and $\left[\mathrm{C}_{8} \mathrm{H}_{5} \mathrm{Cl}_{3} \mathrm{O}_{3}\right]_{(\mathrm{t})}$ is the on-time concentration of 2,4,5- $\mathrm{T}\left(\mathrm{mol} \mathrm{m}^{-3}\right)$.

When related with the COD during electrochemical destruction, theoretical mineralization reaction of 2,4,5-T would need seven moles of oxygen (equation 5) :

$$
\mathrm{C}_{8} \mathrm{H}_{5} \mathrm{Cl}_{3} \mathrm{O}_{3}+7 \mathrm{O}_{2} \rightarrow 8 \mathrm{CO}_{2}+3 \mathrm{HCl}+\mathrm{H}_{2} \mathrm{O}
$$

\section{EXPERIMENTAL}

\section{Electrodes}

The boron-doped diamond (Si/BDD) electrodes were provided and synthesized by the Swiss Center for Electronics and Microtechnology SA, Neuchâtel-Switzerland using the hot filament chemical vapor deposition technique (HF-CVD) on conducting $p$-Si. The obtained diamond film thickness was about $1 \mu \mathrm{m}[18]$.

\section{Chemicals}

2,4,5-T, 2,4,5-trichlorophenol, 2,5-dichlorohydroquinone, 4,6-dichlororesorcinol, and 2,5dihydroxybenzoquinone were purchased from Panreac-Avocado, having more than $98 \%$ purity. Short chains carboxylic acids such as glycolic, glyoxylic, oxalic, malic, maleic, formic and fumaric were reagent grade from Merck and Fluka. Sulfuric, phosphoric and hydrochloric acids and the other solvents used for HPLC were analytical grade from Merck, Fluka, and Aldrich. 


\section{Apparatus and procedure}

Voltammetric and chronoamperometric measurements were obtained with an AutoLab 100 potentiostat/galvanostat at room temperature. Si/BDD plate of $1-\mathrm{cm}^{2}$ geometric area has been used as working electrode. The counter electrode was a platinum wire. Reference electrode was a $\mathrm{Hg} / \mathrm{HgSO} \mathrm{H}_{4} / \mathrm{K}_{2} \mathrm{SO}_{4}$ (sat) inserted in a vitreous Luggin capillary. Current densities are calculated with respect to the area of $1 \mathrm{~cm}^{2}$. Cyclic voltammograms were obtained at different sweep rates without stirring, while during chronoamperometry, the solutions were continuously stirred to prevent eventual decrease in current intensity due to diffusion problems.

Electrolyses were performed in galvanostatic mode. The total organic carbon (TOC) of the solution was determined with a TOC-5050 Shimadzu apparatus, while COD was obtained using a HACH DR2010 analyzer. The ICE during electrolysis has been calculated by means of the relation:

$$
\mathrm{ICE}=4 F V\left[(\mathrm{COD})_{\mathrm{t}}-(\mathrm{COD})_{\mathrm{t}+\Delta \mathrm{t}}\right] /(I \Delta t)
$$

where $(\mathrm{COD})_{\mathrm{t}}$ and $(\mathrm{COD})_{\mathrm{t}+\Delta \mathrm{t}}$ are the COD at times $t$ and $t+\Delta t$ (in $\mathrm{mol} \mathrm{O}_{2} \mathrm{dm}^{-3}$ ), respectively, $I$ is the current (A) and $V$ is the volume of electrolyte $\left(\mathrm{dm}^{3}\right)$.

The peak potential value can be calculated from equation 7 , that also permits the determination of transfer coefficient $(\alpha)$ value:

$$
E_{\mathrm{p}}=\text { const. }-\frac{R T}{2 \alpha n F} \ln v
$$

where $R$ is the gas constant, $T$ is the operating temperature and $v$ is the scan rate during cyclic voltammetry. The diffusion coefficient $D$ is obtained from the Randles-Sevcik equation representative of the current peak $\left(i_{\mathrm{p}}\right)$ and the scan rate $(v)$ dependence:

$$
i_{\mathrm{p}}=2.69 \times 10^{5} n C D^{1 / 2} \mathrm{v}^{1 / 2}
$$

where $n$ is the number of exchanged electrons and $C$, the 2,4,5-T concentration in the solution.

The formation of several organic compounds coming from the electrochemical treatment of 2,4,5-T was followed by means of a Shimadzu series 6 HPLC apparatus fitted with a Supelco Inc Nucleosil C18 - $5 \mu \mathrm{m}$ column for the determination of the aromatic intermediates or with a Supelcogel $\mathrm{H}$ column for the polar oxidation byproducts. Solutions of acetonitrile/water 58:42 with $\mathrm{pH}$ adjusted to 2.1 with $98 \% \mathrm{H}_{3} \mathrm{PO}_{4}$ at a flow rate of $0.8 \mathrm{~mL} / \mathrm{min}$ and $0.13 \%$ phosphoric acid at a flow rate of $0.5 \mathrm{~mL} / \mathrm{min}$ have been used as mobile phases for monitoring, respectively, the evolution of aromatic and carboxylic compounds by HPLC.

\section{Electrolytic system}

Bulk anodic oxidation of the solutions of 2,4,5-T was carried out using an undivided electrochemical flow cell. The anode was a disk of $p$-Si/BDD and the cathode a zirconium plate, both of a geometric area of $50 \mathrm{~cm}^{2}$ with an inter-electrode gap of $10 \mathrm{~mm}$. The electrolyte was stored in a thermo-regulated glass tank and circulated through the electrolytic cell by a centrifugal pump. The electrochemical reactor volume was $V_{\mathrm{E}}=50 \mathrm{~cm}^{3}$ and the reservoir volume $V_{\mathrm{R}}=500 \mathrm{~cm}^{3}$. The value of the mass-transfer coefficient in the cell (determined using the ferri/ferrocyanide couple) was $1.5 \times 10^{-5} \mathrm{~cm}^{2} \mathrm{~s}^{-1}$. 


\section{RESULTS AND DISCUSSION}

\section{Cyclic voltammetry}

Voltammograms of saturated solutions of 2,4,5-T at the potential region of oxygen evolution show an oxidation peak at near $1.75 \mathrm{~V} v s$. SHE, that announces the break down of the $(\mathrm{C}(1)-\mathrm{O})$ - bond of the compound's molecular structure. The produced phenolic intermediates have a great ability to polymerize on the diamond anode surface when oxidation is ruled at lower potentials, meanwhile at higher potentials the degradation process continues to give other quinonic and molecularly lower formulated compounds. Cyclic voltammograms, of the same saturated herbicide solution, performed at different scan rates, are represented in Figure 1. As usually appointed for, the appearance of a lone oxidation peak announces the irreversible characteristic of the oxidation of phenoxy-family compounds on the BDD anodes [19]. The inset kinetic analysis is in acceptable concordance with the theoretical expectance and confirms the diffusion-controlled process during oxidation on the diamond film anode surface. A diffusion coefficient of $9.31 \times 10^{-5} \mathrm{~cm}^{2} \mathrm{~s}^{-1}$ has been obtained from equation 8 . The analysis of the dependence of the peak potential $\left(E_{\mathrm{p}}\right)$ on the logarithm of the scan rate $(\ln v)$ from equation 7 has given an experimental transfer coefficient value $\alpha=0.56$ comparable to that theoretically expected $(\alpha=0.5)$. Cyclic voltammetry of various solutions of different concentrations of 2,4,5$\mathrm{T}$ is represented in Figure 2. The current peak values are perfectly proportional to the concentration of the studied compound. The lower the herbicide concentration is, the lower is the value of the current peak intensity of the corresponding voltammogram. The obtained experimental diffusion coefficient $\left(9.95 \times 10^{-5} \mathrm{~cm}^{2} \mathrm{~s}^{-1}\right)$ from this is close to that obtained before.

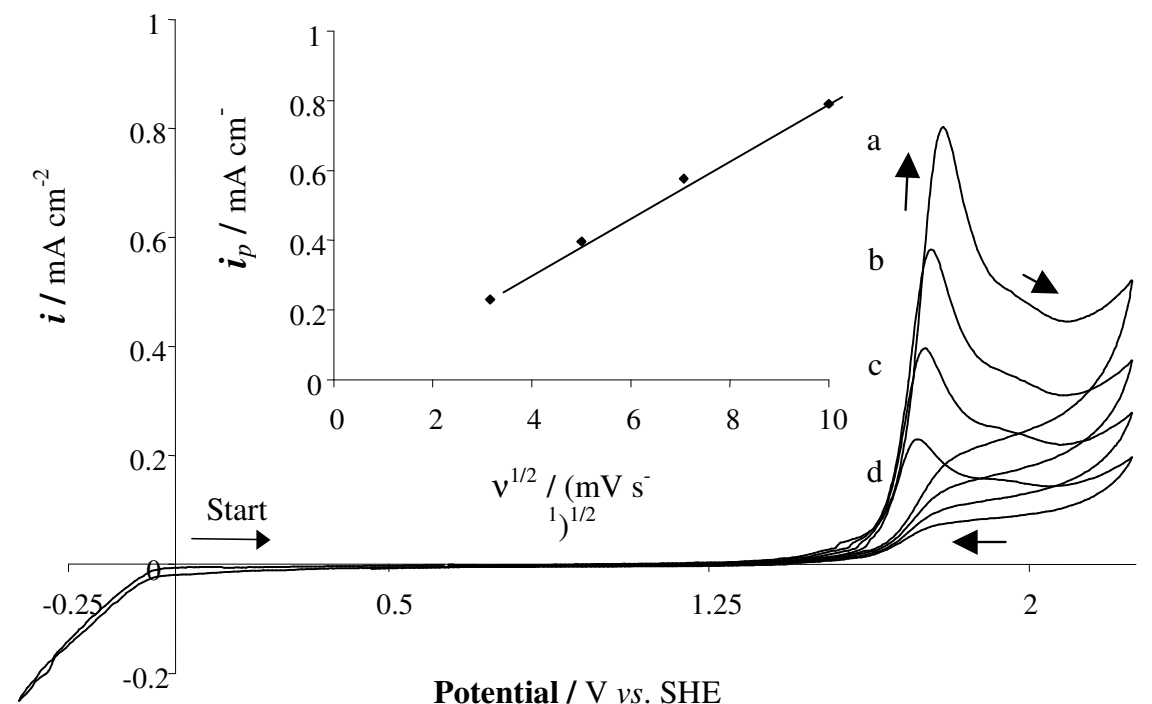

Figure 1. First-cycle voltammograms for $266 \mathrm{ppm}$ 2,4,5-T solution (saturated) in $1 \mathrm{M} \mathrm{HClO}_{4}$ on a BDD anode at $25{ }^{\circ} \mathrm{C}$ and at different scan rates : (a) 100, (b) 50, (c) 25, and (d) 10 $\mathrm{mVs}^{-1}$. Inset: dependence of current peak density $\left(i_{\mathrm{p}}\right)$ on the square root of the scan rate $\left(v^{1 / 2}\right)$.

Bull. Chem. Soc. Ethiop. 2004, 18(2) 


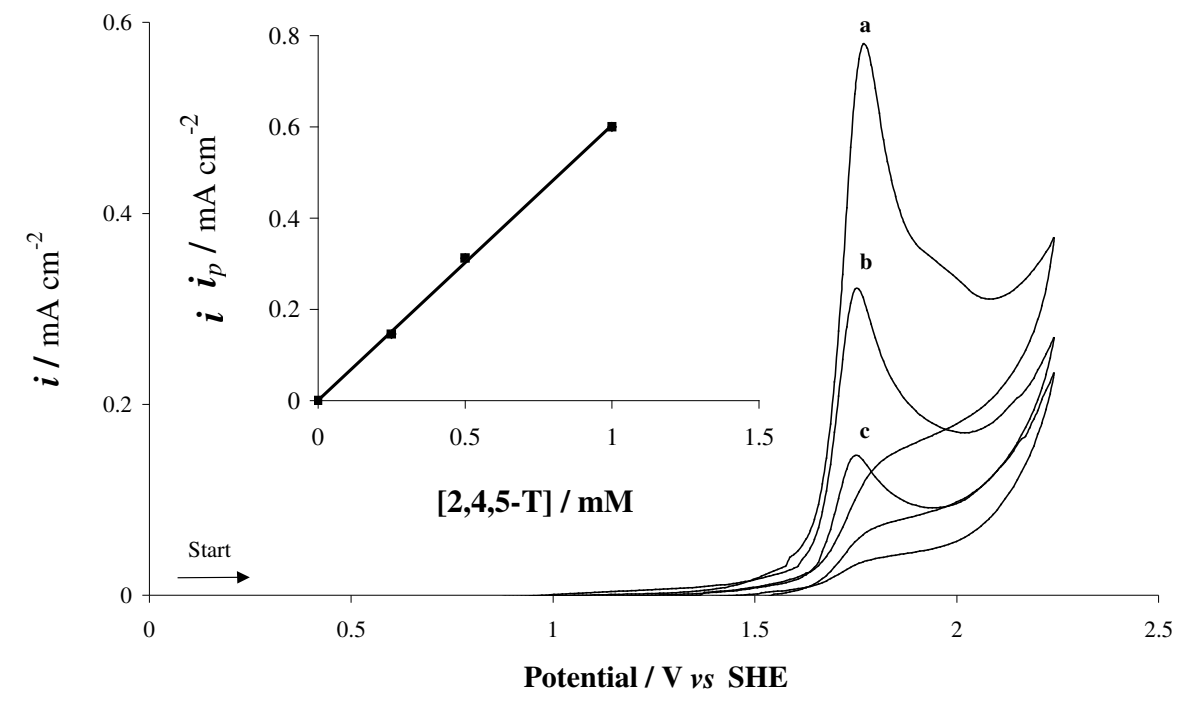

Figure 2. Cyclic voltammograms of solutions of different 2,4,5-T concentrations in $1 \mathrm{M} \mathrm{HClO}_{4}$ at scan rate $50 \mathrm{mV} / \mathrm{s}$ and $\mathrm{T}=25{ }^{\circ} \mathrm{C}$ : (a) 1 , (b) 0.5 and (c) $0.25 \mathrm{mM}$. Inserted figure: evolution of the current peak density $\left(i_{\mathrm{p}}\right)$ with the concentration of 2,4,5-T herbicide.

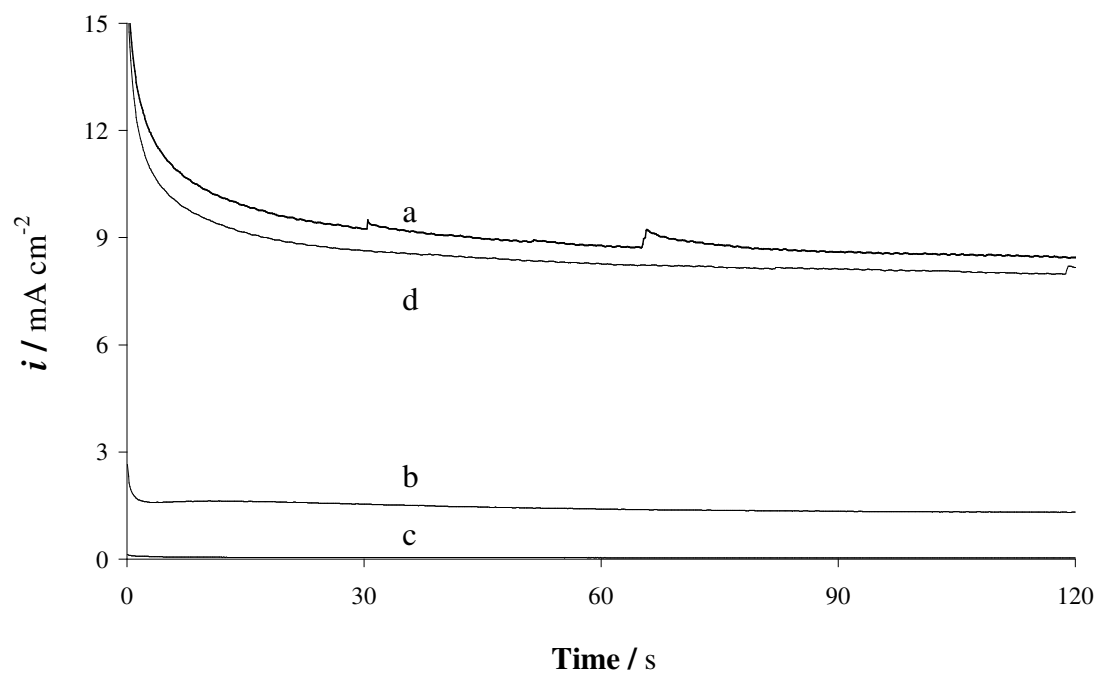

Figure 3. Chronoamperometric illustration of the deactivation and reactivation processes of the BDD anode at low and high potentials in $1 \mathrm{M} \mathrm{HClO}_{4}$ for saturated solutions of 2,4,5-T at $25^{\circ} \mathrm{C}$. (a) curve recorded at high potential $(3.25 \mathrm{~V} v \mathrm{~s}$. SHE), (b,c) curves recorded at low potential (1 V vs. SHE) and after washing with isopropanol, respectively, and (d) curve recorded at high potential after $60 \mathrm{~s}$ of polarization at $3.25 \mathrm{~V} v s$. SHE.

Bull. Chem. Soc. Ethiop. 2004, 18(2) 


\section{Chronoamperometry}

Chronoamperometric measurements on saturated solutions of 2,4,5-T have been performed within the potential region of stability of the electrolyte and of water decomposition as illustrated in Figure 3. A horizontal curve parallel to the abscise is observed at $3.25 \mathrm{~V} v$ s. SHE, when water decomposes, indicating the continuous oxidation of the organic compounds present in the medium and the activated state of the BDD anode (curve a). When the measurements are done at low potential, the oxidation threshold (curve b) is lower due to the formation of a film on the BDD electrode surface that results on its deactivation. Reactivation is not obtained by washing the electrode surface with isopropanol or water (curve c). It is noteworthy that after repolarization of near 60-120 s at potentials superior than $2 \mathrm{~V} v s$. SHE, the BDD anode recovers its initial activity, as shown in curve d. At high oxidation potentials, the diamond anode generates much more hydroxyl radicals that destroy the polymeric film formerly deposed at its surface. As seen, boron doped diamond electrodes offer the possibility to work and to destroy organic pollutants over a wide range of potentials.

\section{Degradation behavior}

Saturated synthetic solutions of $266 \mathrm{ppm}$ 2,4,5-T herbicide have been degraded at current densities of $2,8,15$ and $30 \mathrm{~mA} \mathrm{~cm}$ and at $35{ }^{\circ} \mathrm{C}$. During all the oxidation process, the total dissolved organic carbon (TOC) and, consequently, the COD straightly go down at the initial low charges corresponding to the current-limit domain and later follow an exponential trend corresponding to the mass-transport domain (see Figure 4 and 5). Complete elimination of the organic pollutants occurs in the cases studied at specific charges $(Q)$ between 2-15 $\mathrm{A} \mathrm{h} \mathrm{dm}^{-3}$ depending on the current density applied. These specific charges correspond to 4-6 hours of process for current densities from $8-15 \mathrm{~mA} \mathrm{~cm}^{-2}$ and 9 hours for $2 \mathrm{~mA} \mathrm{~cm}$. These relatively large-time intervals of degradation can be explained by the fact that at a certain moment of the process the initial pollutant and the obtained byproducts are transformed into carboxylic acids which are relatively more difficult to oxidize.

Figure 5 gives the corresponding trend of the COD, with the ICE inset, consecutive to the elimination of the total dissolved organic carbon present in the solution. The instant current efficiency rapidly decreases (see inset in Figure 5) even at lower 2-mA cm${ }^{-2}$ charge instead of being maximum as observed in former study [19]. This fact can be explained by the low charge of contaminants $(\leq 1 \mathrm{mM})$ contrarily to the habitually related that are usually four and more times greater. Furthermore, practical COD and ICE trend (dark line) is perfectly reproduced by the theoretical model trend explained above.

\section{Kinetics and reaction intermediates}

Dependence of the herbicide's trend with current density. The behavior of the same 2,4,5-T saturated herbicide solutions during electrolysis has been followed by HPLC in the defined range of current densities and at $35^{\circ} \mathrm{C}$ as represented in Figure 6. It is noteworthy that the initial herbicide disappears from the electrolyzed medium in 4-5 $\mathrm{h}$ corresponding to specific charges of 1.5-15 $\mathrm{A} \mathrm{h} \mathrm{dm}^{-3}$, respectively, in the interval of current densities of $2-30 \mathrm{~mA} \mathrm{~cm}$. Kinetic analyses are inserted in Figure 6 . The oxidation process is determined by a pseudo-first order reaction, with a $k$ value of $0.016 \mathrm{~min}^{-1}$ (correlation coefficient, $r=0.99$ ) for the high current densities and $0.013 \mathrm{~min}^{-1}(r=0.99)$ at $2 \mathrm{~mA} \mathrm{~cm}^{-2}$. Hydroxyl radicals attack is similar in these considered cases, but they are electrogenerated in less quantity at lower current densities, what explains the slower destruction rate of the herbicide at $2 \mathrm{~mA} \mathrm{~cm}^{-2}$. 


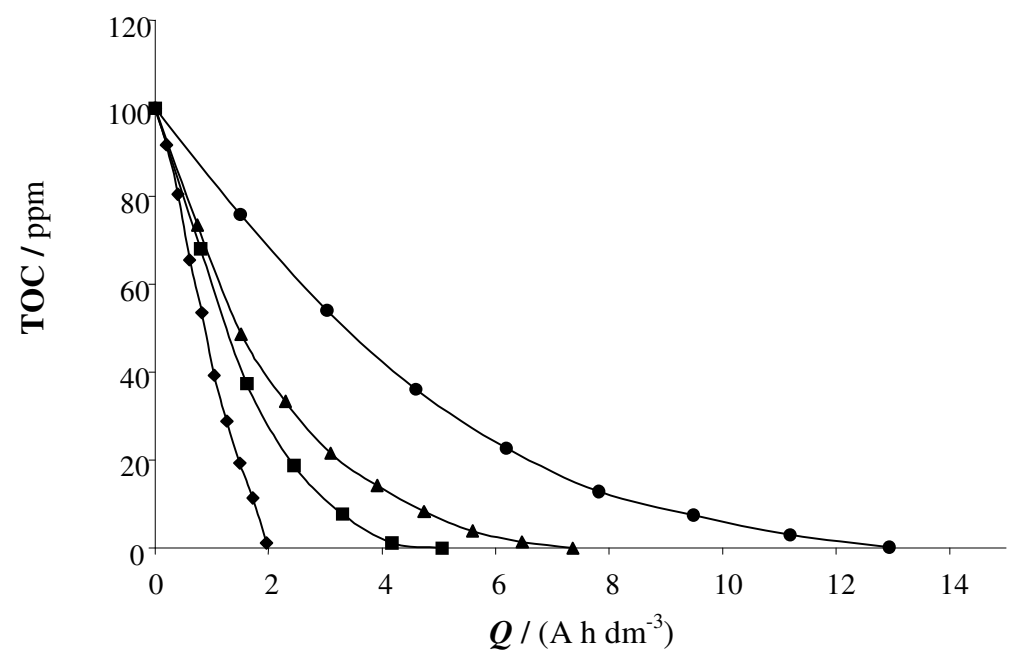

Figure 4. Effect of current density on anodic oxidation of saturated 2,4,5-T herbicide solutions in $1 \mathrm{M} \mathrm{HClO}_{4}$ on a BDD electrode at $35^{\circ} \mathrm{C}$. Current density: $(\bullet) 30,(\boldsymbol{\Delta}) 15,(\bullet) 8,(\bullet)$ $2 \mathrm{~mA} \mathrm{~cm}^{-2}$.

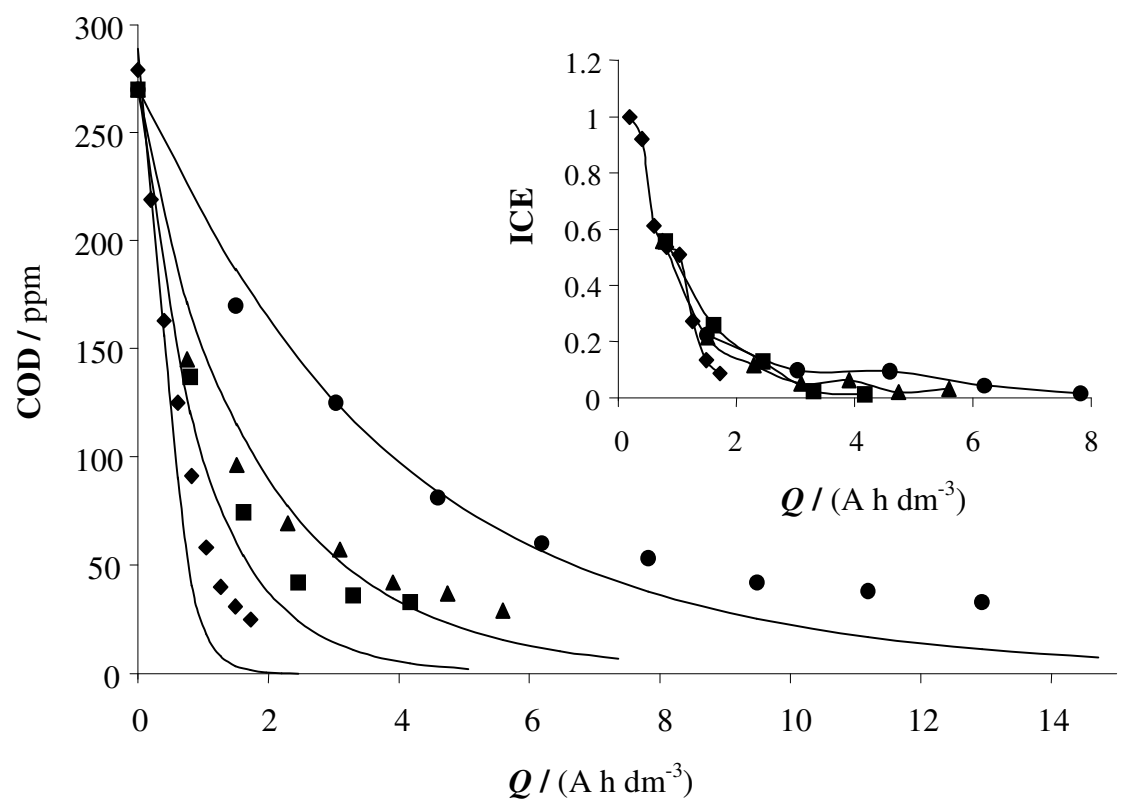

Figure 5. Effect of current density on the COD evolution during electrolysis of saturated 2,4,5-T herbicide solutions in $1 \mathrm{M} \mathrm{HClO}_{4}$ on a BDD electrode at $35^{\circ} \mathrm{C}$. Current density: $(\bullet)$ $30,(\Delta) 15,(\boldsymbol{\bullet}) 8,(\diamond) 2 \mathrm{~mA} \mathrm{~cm} \mathrm{~cm}^{-2}$. Solid curves for COD and ICE correspond to the theoretical values generated by the model illustrated in Table 1 .

Bull. Chem. Soc. Ethiop. 2004, 18(2) 


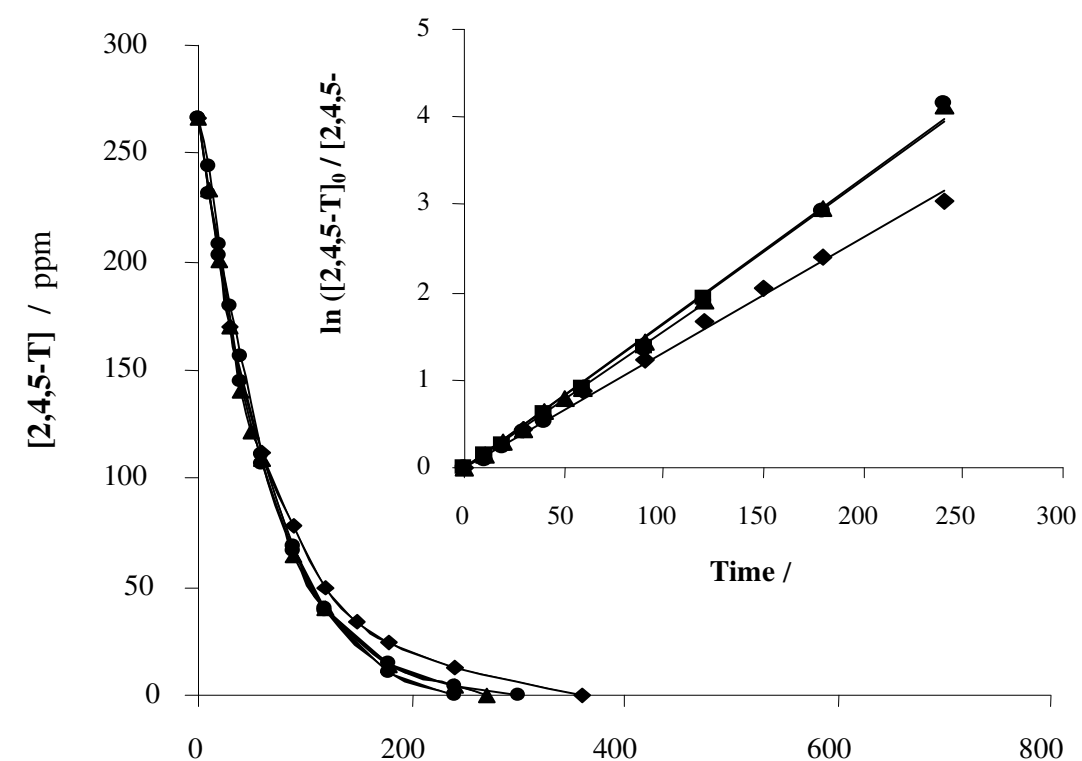

Time / min

Figure 6. 2,4,5-T concentration decays with electrolysis time during the anodic oxidation of 500 $\mathrm{mL}$ herbicide solutions in $1 \mathrm{M} \mathrm{HClO}_{4}$ on the $\mathrm{BDD} / \mathrm{Zr}$ system at current densities of: $(\bullet)$ $30,(\Delta) 15,(\bullet) 8$ and $(\bullet) 2 \mathrm{~mA} \mathrm{~cm}{ }^{-2}$ and at $35^{\circ} \mathrm{C}$. The inset gives the corresponding kinetic analysis for the herbicide assuming a pseudo first-order reaction.

Detection of 2,4,5-T oxidation by-products. Experiments have been performed in the same range of current densities. Reverse phase chromatography analysis reveals trace concentrations of 2,4,5-T herbicide aromatic intermediates of degradation such as 2,4,5-trichlorophenol, 2,5dichlorohydroquinone, 4,6-dichlororesorcinol, 2,5-dihydroxybenzoquinone at current density of $30 \mathrm{~mA} \mathrm{~cm}$, while they subsist in the electrolyzed medium up to complete transformation of 2,4,5-T when operating at $2 \mathrm{~mA} \mathrm{~cm}^{-2}$. Ion exclusion chromatography has permitted to determine the short chains carboxylic acids intermediates. Glycolic, glyoxylic, malic, maleic and fumaric acids have been mainly depicted and are transformed into formic and oxalic recognized as much more recalcitrant to oxidation. Mineralization of 2,4,5-T herbicide achieves with the latter transformation of these ultimate byproducts into $\mathrm{CO}_{2}$ and $\mathrm{H}_{2} \mathrm{O}$.

\section{CONCLUSIONS}

We have achieved the complete mineralization of 2,4,5-T herbicide in its saturated aqueous synthetic solutions in a large range of current densities, showing the great possibility to remove this pollutant from contaminated waters or industrial effluents on boron-doped diamond thin film layer electrode used as anode. The extreme stability of the BDD electrode and its high oxygen over-voltage have permitted the destruction of 2,4,5-trichorophenoxyacetic acid herbicide; this confirmed by monitoring the concomitant evolution of the TOC and COD and the ICE. By using cyclic voltammetry and chromatographic techniques of analysis we have 
described the evolution of the same 2,4,5-T herbicides during electrolysis and determined its oxidation intermediates. Electrochemical oxidation methods using BDD anodes constitute a viable and environmental friendly way for waters and wastewater decontamination that allows complete mineralization of organic pollutants without any need in addition of catalyst.

\section{ACKNOWLEDGMENTS}

The authors thank the CSEM, Swiss Center for Electronics and Microtechnology SA, Neuchâtel, Switzerland for preparing the boron-doped diamond electrodes, and the AECI, Spain Agency of International Cooperation, for the grant accorded to Birame Boye. This paper is dedicated to the memory of MAAM NDEYE MBOGNE NDOYE.

\section{REFERENCES}

1. Kaba, L.; Hitchens, G.D.; Bockris, J. O’M. J. Electrochem. Soc. 1990, 137, 1341.

2. Feng, J.; Houk, L.L.; Johnson, D.C.; Lowery, S.N.; Carey, J.J. J. Electrochem. Soc. 1995, $142,3626$.

3. Wu, Z.C.; Zhou, M.H. Environ. Sci. Technol. 2001, 35, 2698.

4. Kotz, R.; Stucki, S.; Carcer, B. J. Appl. Electrochem. 1991, 21, 14.

5. Stucki, S.; Kotz, R.; Carcer, B.; Suter, W. J. Appl. Electrochem. 1991, 21, 99.

6. Comninellis, C.; Pulgarin, C. J. Appl. Electrochem. 1991, 21, 703; J. Appl. Electrochem. 1993, 23, 108.

7. Johnson, S.K.; Houk, L.L.; Feng, J.; Houk, R.S.; Johnson, D.C. Environ. Sci. Technol. 1999, 33, 2638.

8. Comninellis, C.; Nerini, A. J. Appl. Electrochem. 1995, 25, 23.

9. Rodgers, J.D.; Bunce, N.J. Environ. Sci. Technol. 2001, 35, 406.

10. Boye, B.; Brillas, E.; Dieng, M.M. J. Electroanal. Chem. 2003, 540, 25.

11. Ponce De Leon, C.; Pletcher, D. J. Appl. Electrochem. 1995, 25, 307.

12. Harrington, T.; Pletcher, D. J. Electrochem. Soc. 1999, 146, 2983.

13. Oturan, M.A. J. Appl. Electrochem. 2000, 30, 475.

14. Panizza, M.; Michaud, P.-A.; Cerisola, G.; Comninellis, C. Electrochem. Commun. 2001, 3, 336.

15. Marselli, B.; Garcia-Gomez, J.; Michaud, P.-A.; Rodrigo, M.A.; Comninellis, C. J. Electrochem. Soc. 2003, 150, D79.

16. Lissens, G.; Peters, J.; Verhaege, M.; Pinoy, L.; Verstraete, W. Electrochim. Acta 2003, 48, 1655.

17. Panizza, M.; Michaud, P.-A.; Cerisola, G.; Comninellis, C. J. Electroanal. Chem. 2001, 507, 206.

18. Haenni, W.; Baumann, H.; Comninellis, Ch.; Gandini, D.; Niedermann, P.; Perret, A.; Skinner, N. Diamond Rel. Mat. 1998, 7, 569.

19. Boye, B.; Marselli, B.; Michaud, P.-A.; Dieng, M.M.; Brillas, E.; Comninellis, C. New Diamond Front. Carbon Technol. 2002, 12, 63. 